\title{
Effect of Co Doping on Structural and Optical Properties of NiO Thin Films Prepared By Chemical Spray Pyrolysis Method
}

\author{
Nabeel A. Bakr*, Sabah A. Salman, Ahmed M. Shano \\ Department of Physics, College of Science, University of Diyala, Diyala, Iraq \\ *E-mail address: nabeelalibakr@yahoo.com
}

\begin{abstract}
In this work, nickel-cobalt oxide $\left(\mathrm{Ni}_{(1-\mathrm{x})} \mathrm{Co}_{\mathrm{x}} \mathrm{O}\right)$ thin films, where $\mathrm{x}=0,4,6$ and $8 \%$ have been successfully deposited on glass substrates by chemical spray pyrolysis (CSP) technique at substrate temperature of $\left(400^{\circ} \mathrm{C}\right)$ and thickness of about $300 \mathrm{~nm}$. The structural and optical properties of these films have been studied using XRD, AFM, and UV-Visible spectroscopy. The XRD results showed that all films are polycrystalline in nature with cubic structure and preferred orientation along (111) plane. The crystallite size was calculated using Scherrer formula and it is found that the undoped $\mathrm{NiO}$ sample has maximum crystallite size $(51.16 \mathrm{~nm})$. AFM results showed homogenous and smooth thin films. The absorbance and transmittance spectra have been recorded in the wavelength range of (300$900) \mathrm{nm}$ in order to study the optical properties. The optical energy gap for allowed direct electronic transition was calculated using Tauc equation. It is found that the band gap decreases as the Coconcentration increases and the band gap values were in the range of 3.58-3.66 eV and $3.58 \mathrm{eV}$ for the prepared Nickel-Cobalt Oxide thin films. The Urbach energy increases as the Co-concentration increases and the Urbach. The optical constants including (absorption coefficient, real and imaginary parts of dielectric constant) were also calculated as a function of photon energy. Refractive index and extinction coefficient for Nickel- Cobalt Oxide thin films were estimated as a function of wavelength.
\end{abstract}

Keywords: NiO thin films; Co Doping; Chemical Spray Pyrolysis; Optical Properties; Structural Properties

\section{INTRODUCTION}

Nickel(II) oxide is the chemical compound with the formula NiO. It is notable as being the only well characterized oxide of nickel. The mineralogical form of $\mathrm{NiO}$, bunsenite, is very rare. $\mathrm{NiO}$ can be prepared by multiple methods. Upon heating above $400{ }^{\circ} \mathrm{C}$, nickel powder reacts with oxygen to give $\mathrm{NiO}$. In some commercial processes, green nickel oxide is made by heating a mixture of nickel powder and water at $1000{ }^{\circ} \mathrm{C}$, the rate for this reaction can be increased by the addition of $\mathrm{NiO}$ [1]. The simplest and most successful method of preparation is through pyrolysis of nickel(II) compounds such as the hydroxide, nitrate, and carbonate, which yields a light green powder. Synthesis from the elements by heating the metal in oxygen can yield grey to black powders which indicates nonstoichiometry [2]. NiO adopts the $\mathrm{NaCl}$ structure, with octahedral $\mathrm{Ni}(\mathrm{II})$ and $\mathrm{O}_{2}^{-}$. Nickel oxide $(\mathrm{NiO})$ has a density of $(6.67$ 
$\left.\mathrm{g} / \mathrm{cm}^{3}\right)$ and molecular weight of $(74.69 \mathrm{~g} / \mathrm{mol})$. Its melting point is $\left(1955^{\circ} \mathrm{C}\right)$ [3]. Nickel oxide thin films have different applications such as, an antiferromagnetic material [4], p-type transparent conducting films [5], electro catalysis, positive electrode in batteries, fuel cell, a material for electro-chromic display devices, solar thermal absorber [6]. Different techniques such as sol-gel, spray pyrolysis, ion beam sputtering, magnetic sputtering, and pulsed laser deposition have been used for deposition of pure and doped Co films [7]. Cobalt (Co) lies with the transition metals on the periodic table. The atomic number of Cobalt is 27 with an atomic mass of 58.933195 [8]. Cobalt is a sturdy, gray metal which resembles iron and nickel. In the present paper, we report the effect of (Co) doping on the optical and structural properties of $\mathrm{NiO}$ films prepared by chemical spray pyrolysis technique.

\section{EXPERIMENTAL PROCEDURE}

Chemical spray pyrolysis technique was used to deposit undoped and Co-doped (NiO) films on glass substrates at temperature of $\left(400{ }^{\circ} \mathrm{C}\right)$. Reagent grade nickel nitrate hexahydrate $\mathrm{Ni}\left(\mathrm{NO}_{3}\right)_{2} \cdot 6 \mathrm{H}_{2} \mathrm{O}$ and cobalt nitrate hexahydrate $\mathrm{Co}\left(\mathrm{NO}_{3}\right)_{2} \cdot 6 \mathrm{H}_{2} \mathrm{O}$ were used as starting chemicals. Both metal nitrates were dissolved separately in didtilled water at the concentration of $0.1 \mathrm{M}$. Final solutions were prepared by mixing the two initial solutions in appropiriate volumetric proportions to get various concentrations of Co $(0,4,6,8) \mathrm{wt}$. \%. The resultant solution was sprayed on glass substrate. Other deposition conditions such as spray nozzle substrate distance $(30 \mathrm{~cm})$, spray time $(10 \mathrm{~s})$, spray interval $(2 \mathrm{~min})$ and pressure of the carrier gas (1.5 bar) were kept constant for each concentration. The X-ray diffraction patterns for the prepared films were obtained in a (Shimadzu XRD-6000) goniometer using copper target $(\mathrm{CuK} \alpha, 1.5418 \AA$ ) and Atomic Force Microscopy (AFM) micrographs were recorded by using scanning probe microscope type (SPM- AA3000), contact mode, supplied by Angstrom Advanced Inc. Optical properties in the wavelength range of (300-900) nm were investigated by using UV-VIS-NIR spectroscopy (Shimadzu, UV-1800).

\section{RESULTS AND DISCUSION}
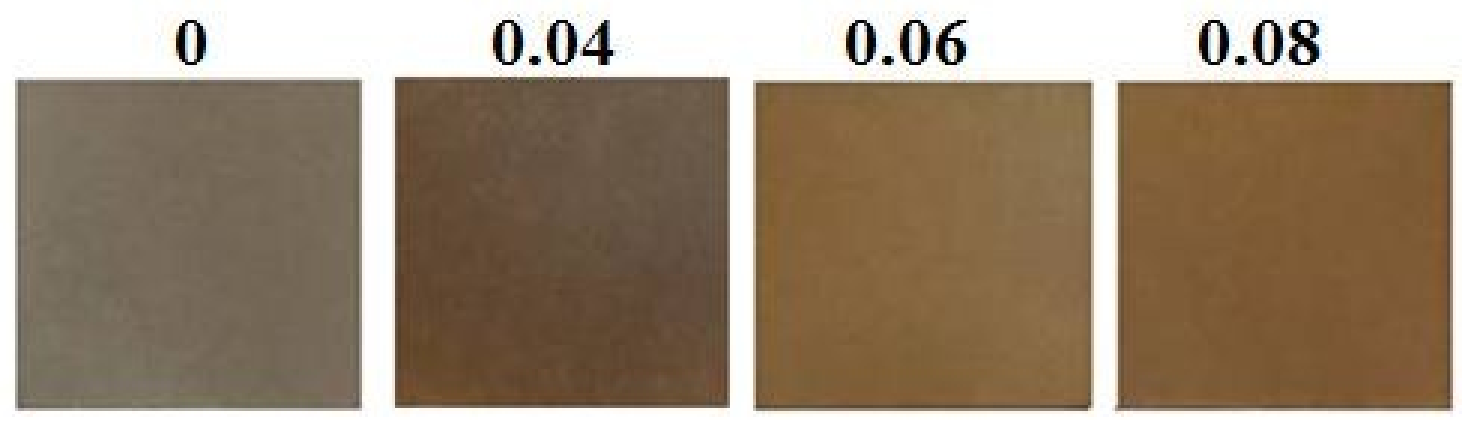

Figure 1. Photo image of $\left(\mathrm{Ni}_{(1-x)} \mathrm{Co}_{x} \mathrm{O}\right)$ thin films, where $\mathrm{x}=0,4,6$ and $8 \%$.

Figure (1) shows the photo image of Nickel-Cobalt Oxide $\left(\mathrm{Ni}_{(1-\mathrm{x})} \mathrm{Co}_{\mathrm{x}} \mathrm{O}\right)$ thin films, where $\mathrm{x}=0,4,6$ and $8 \%$. It is reported that the stoichiometrically correct $\mathrm{NiO}$ thin films are expected to have green color [2]; however, the undoped $\mathrm{NiO}$ thin film deposited in the present study has black-grey color which can be attributed to non-stoichiometry of the deposited 
material. It can also be observed that the Co-doped $\mathrm{NiO}$ thin films are accompanied by a color change from black to orange. This change of color is attributed to the cobalt doping.

\section{1. Structural analysis}

XRD patterns of the Co-doped nickel oxide films are shown in Figure (2). It can be noticed that all the patterns exhibit diffraction peaks around $\left(2 \theta \sim 37^{\circ}, 43^{\circ}\right.$ and $\left.63^{\circ}\right)$ referred to (111), (200) and (220) favorite directions respectively which is in agreement with the Joint Committee of Powder Diffraction Standards (JCPDS) card number 04-0835. The strongest peak occurs at $2 \theta \sim 37^{\circ}$ which is referred to (111) plane. The positions of the peaks and the presence of more than one diffraction peak lead to the conclusion that the films are polycrystalline in nature with a cubic crystalline structure, which is in agreement with other reports $[10,11]$.

It can be noticed that $2 \theta$ for (111) direction decreases with increasing the Coconcentration as shown in Table (1). It can be noticed also that the lattice constant $\left(a_{0}\right)$ increases as the Co-concentration increases. It should be mentioned here that the standard $\mathrm{a}_{\mathrm{o}}$ value for $\mathrm{NiO}$ is $4.176 \AA$ which indicates that the unodoed $\mathrm{NiO}$ film has the nearest $\mathrm{a}_{\mathrm{o}}$ value to the standard lattice constant.

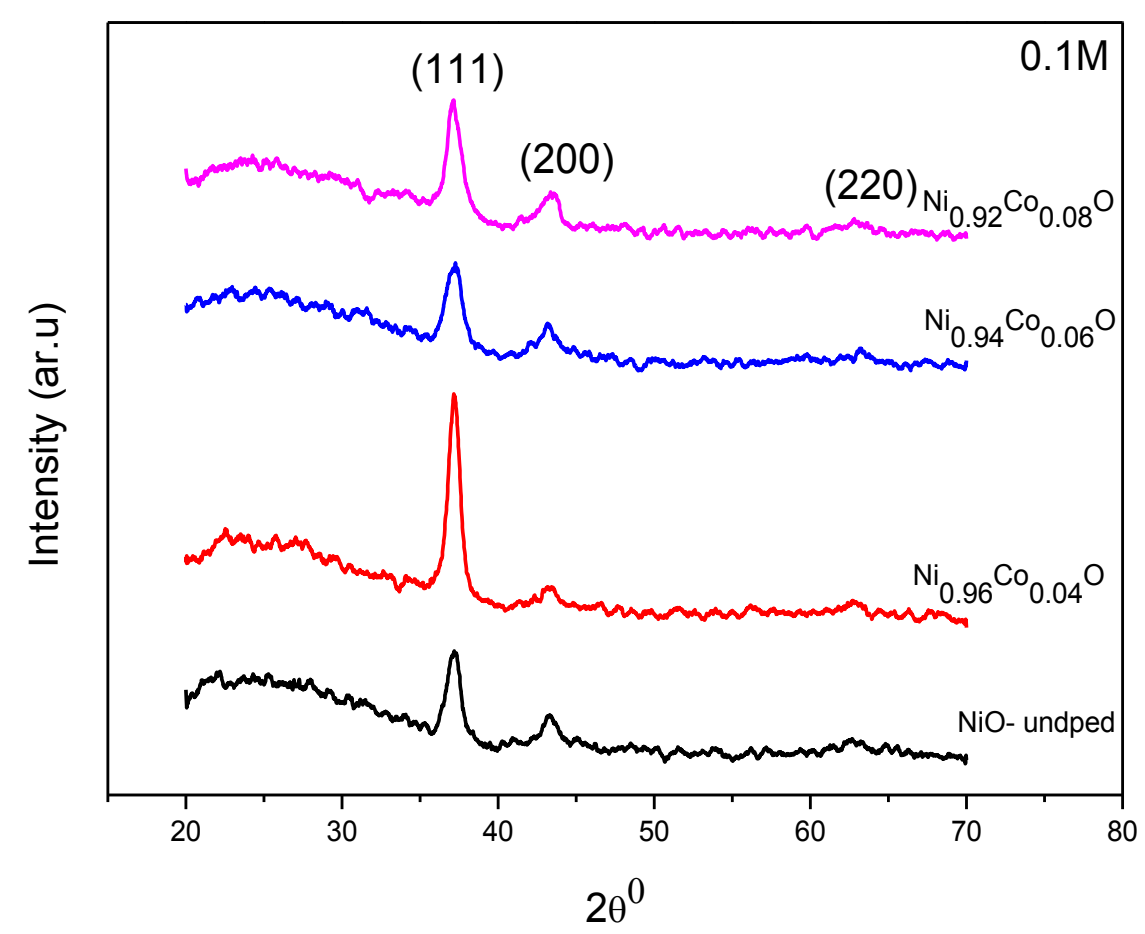

Figure 2. XRD patterns of Co-doped Nickel Oxide thin films. 
The average crystallite size for the films can be determined using Williamson-Hall (WH) formula shown below [12]:

$$
\beta_{h k l} \cos \theta=\left(\frac{\mathrm{K} \lambda}{\mathrm{D}}\right)+4 \mathrm{~S} \sin \theta
$$

where $\beta_{\mathrm{hkl}}$ is full width of half maximum, $\mathrm{D}$ is the average crystallite size, $\mathrm{k}$ is constant and was assumed to be equal to $0.9, \lambda$ is wavelength for $\mathrm{Cu}$ target for XRD instrument, $\theta$ is Bragg's angle for all peaks, and $S$ is the microstrain in the film. If $\beta \cos \theta$ is plotted with respect to $4 \sin \theta$ for all peaks, strain and crystallite size can be calculated from the slope and $y$-intercept of the fitted line respectively as shown in Figure (3).

The average crystallite size for the all films is also calculated for (111) direction by Scherrer formula by using the relation [13]:

$$
\mathrm{D}_{\mathrm{av}}=\frac{\mathrm{K} \lambda}{\beta \cos \theta}
$$

It is observed that the crystallite size for the Nickel-Cobalt Oxide thin films decrease rapidly as the Co-concentration increases from 0 to 0.04 to reach its minimum value of $(8.22 \mathrm{~nm})$. The crystallite size then increases as the Co-concentration increases further to reach value of $(10.1 \mathrm{~nm})$ as shown in Figure (4). These results agree qualitatively with the results of crystallite size obtained by Williamson-Hall method as shown in Table (1). The microstrain in the films is induced during the growth of thin films by varying displacements of the atoms with respect to their reference lattice position [14]. All values of microstrain were negative which indicates the occurrence of compression in the lattice, as shown in Table (1).

\begin{tabular}{|c|c|c|c|c|}
\hline Cobalt concentration & 0 & 0.04 & 0.06 & 0.08 \\
\hline $2 \Theta(\mathrm{deg})$ & 37.3854 & 37.1893 & 37.186 & 37.141 \\
\hline$h k l$ & $(111)$ & $(111)$ & $(111)$ & $(111)$ \\
\hline $\mathrm{d}(\AA)$ & 2.41167 & 2.41571 & 2.41969 & 2.416 \\
\hline (FWHM) (rad) & 0.0028 & 0.0134 & 0.01777 & 0.0144 \\
\hline$\left(D_{a v}\right) n m$ Scherrer & 51.16 & 10.85 & 8.22 & 10.1 \\
\hline$\left(D_{\mathrm{av}}\right) \mathrm{nm} \mathrm{W}-\mathrm{H}$ & 45.01 & 6.48 & 4.73 & 5.46 \\
\hline Micro strain $\mathrm{S} * 10^{-3}$ & -0.62 & -9.43 & -13.07 & -11.9 \\
\hline $\begin{array}{c}\text { Lattice Constants a。 } \\
(\AA)\end{array}$ & 4.1771 & 4.1896 & 4.1841 & 4.185 \\
\hline $\mathrm{T}_{\mathrm{c}}$ & 1.72 & 2.46 & 1.68 & 2.18 \\
\hline
\end{tabular}

Table 1. Structural parameters of Co-doped Nickel Oxide thin films. 
The texture coefficient $\left(T_{c}\right)$ represents the texture of a particular plane, in which greater than unity values imply that there are numerous of grains in that particular direction. The texture coefficients $\mathrm{T}_{\mathrm{c}}(h k l)$ for all samples have been calculated from the X-ray data using the well-known formula [15]:

$$
T_{C}(h k l)=\frac{I(h k l) / I_{0}(h k l)}{N_{r}^{-1} \sum I(h k l) / I_{0}(h k l)}
$$

where $\mathrm{I}(h k l)$ is the measured intensity, $\mathrm{I}_{0}(h k l)$ taken from the JCPDS data, $\left(\mathrm{N}_{\mathrm{r}}\right)$ is the reflection number and $(h k l)$ is Miller indices. The texture coefficient is calculated for crystal plane (111) of the undoped and Co- doped NiO films. All values of texture coefficient were greater than 1 which indicates the abundance of grains in the (111) direction.

\section{2. (AFM) Result}
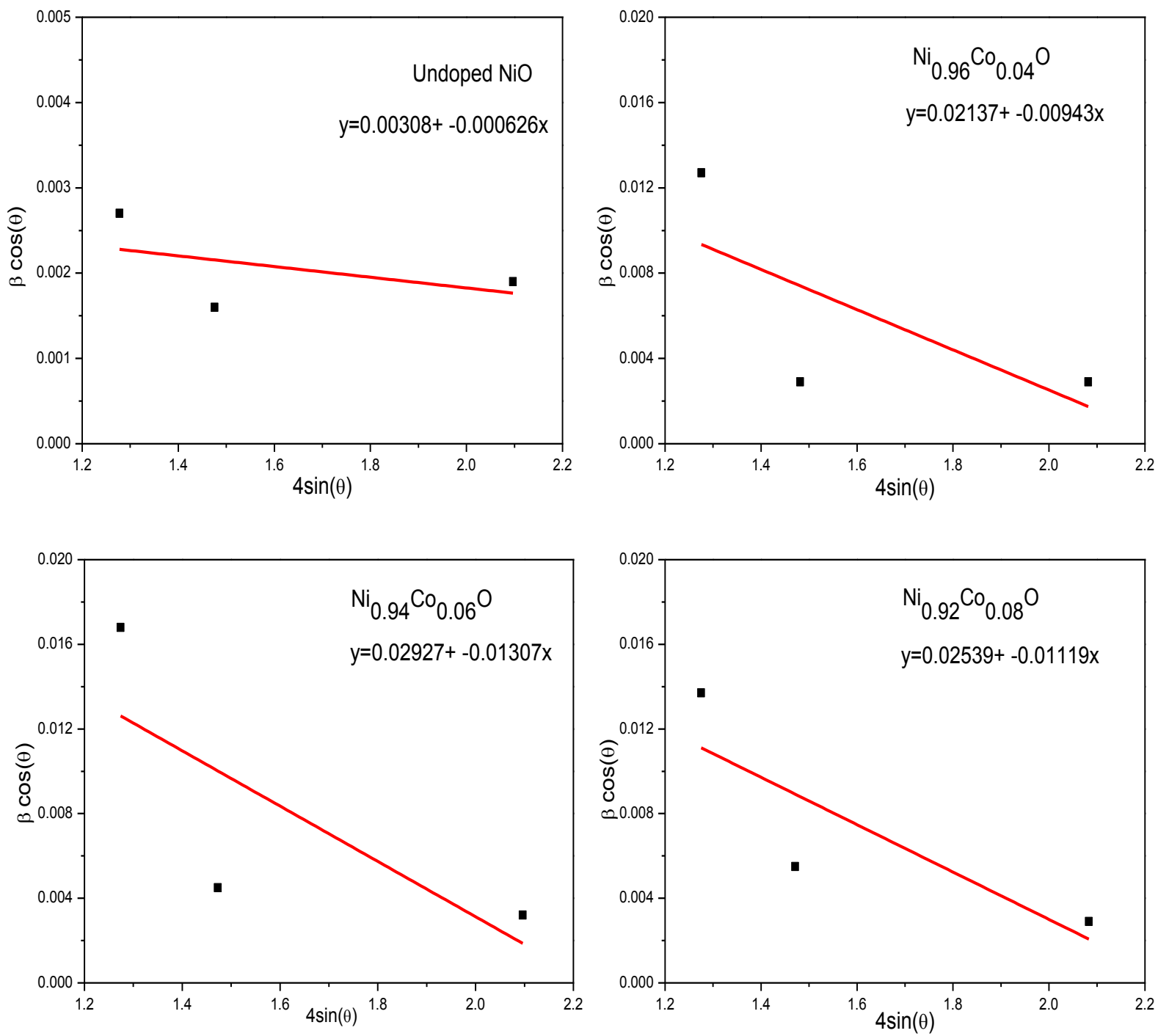

Figure 3. W-H analysis for Co-doped Nickel Oxide thin films. 
The 3D AFM micrographs of Co-doped Nickel Oxide thin films are shown in Figure (5). The size of the scanned area was $(2 \times 2) \mu \mathrm{m}^{2}$. The images show homogenous and smooth films. AFM results showed homogenous and smooth thin films. The average grain size, average roughness and root mean square (RMS) roughness for all samples estimated from

AFM, are given in Table (2). The undoped NiO sample has highest average grain size, average roughness and RMS roughness of the film surface. The increase in the crystallite size may be caused by columnar grain growth in the structure which is in agreement with other studies [11].

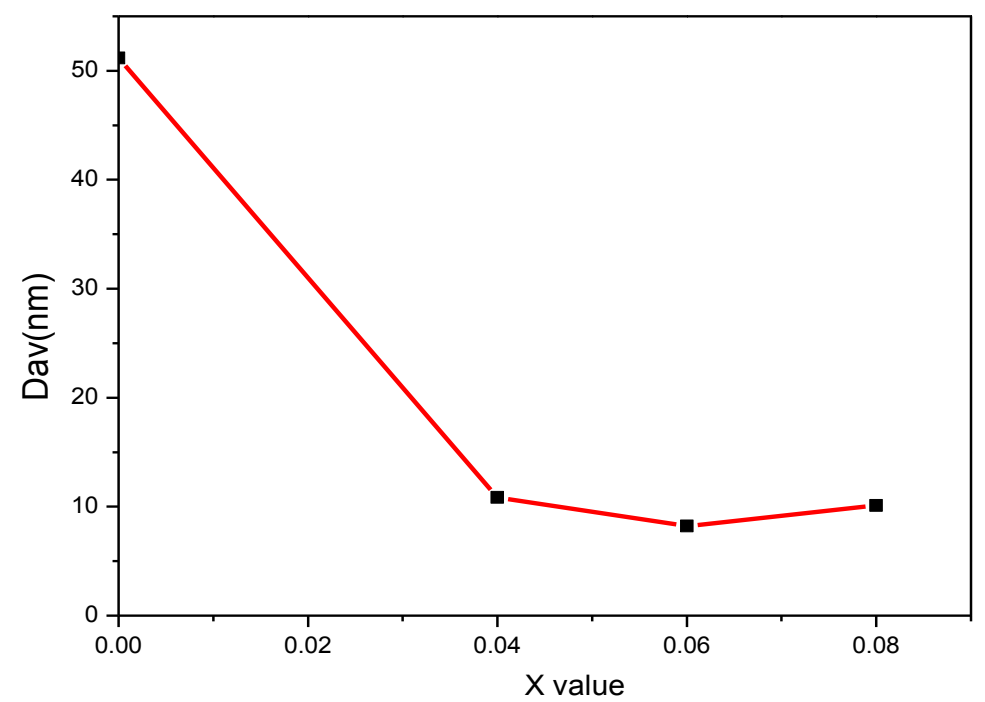

Figure 4. The crystallite size $\left(D_{a v}\right)$ of Nickel-Cobalt Oxide thin films.

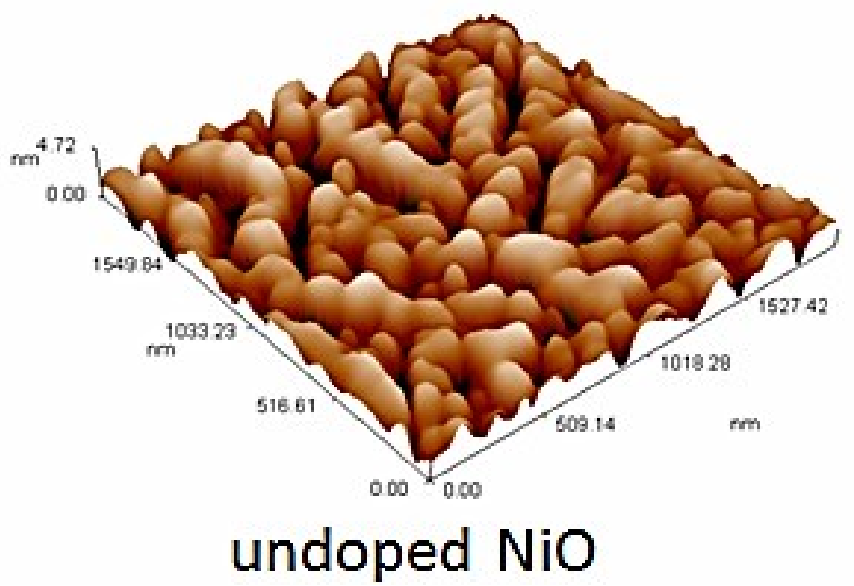




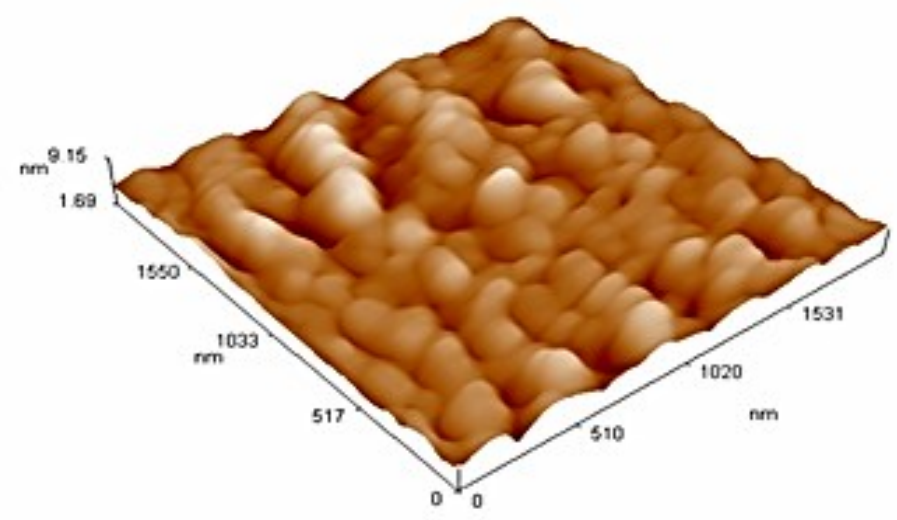

$\mathrm{Ni}_{0.94} \mathrm{Co}_{0.06} \mathrm{O}$

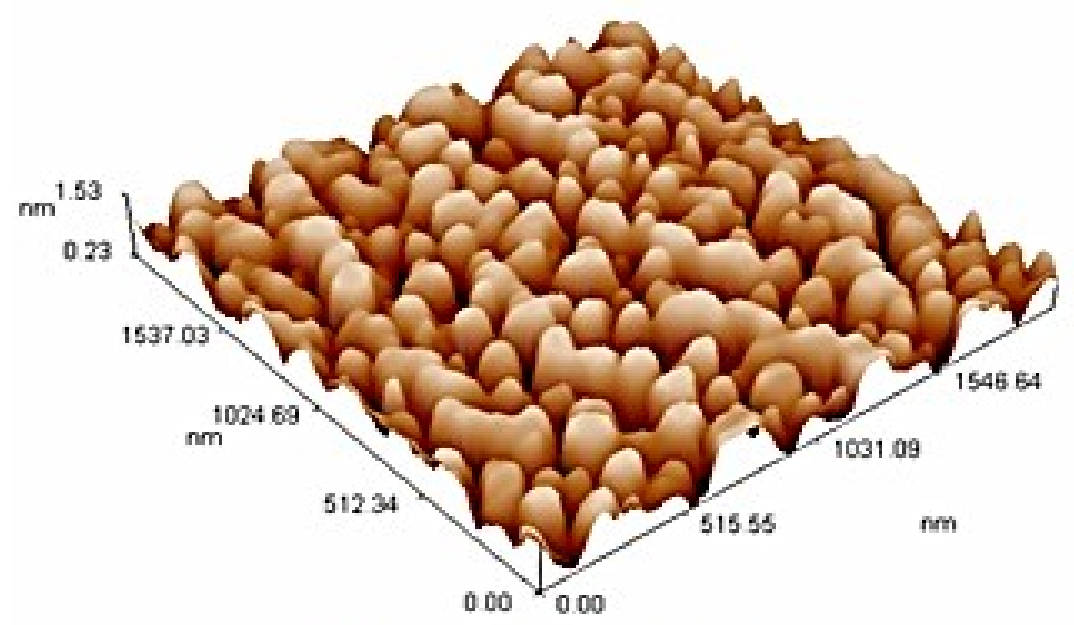

$\mathrm{Ni}_{0.92} \mathrm{Co}_{0.08} \mathrm{O}$

Figure 5. 3D AFM images of some of deposited films.

Table 2. Surface roughness, root mean square (RMS) and grain size of Co-doped Nickel Oxide thin films.

\begin{tabular}{|c|c|c|c|}
\hline Samples & $\begin{array}{c}\text { Surface } \\
\text { roughness } \\
(\mathrm{nm})\end{array}$ & $\begin{array}{c}\text { RMS } \\
(\mathrm{nm})\end{array}$ & $\begin{array}{c}\text { Grain } \\
\text { size }(\mathrm{nm})\end{array}$ \\
\hline Undoped NiO & 0.89 & 1.05 & 133.8 \\
\hline $\mathrm{Ni}_{0.94} \mathrm{Co}_{0.06} \mathrm{O}$ & 0.634 & 0.829 & 131.15 \\
\hline $\mathrm{Ni}_{0.92} \mathrm{Co}_{0.08} \mathrm{O}$ & 0.247 & 0.293 & 88.84 \\
\hline
\end{tabular}




\section{3. Optical analysis}

Optical absorption spectra of the films in spectral range of $(300-900 \mathrm{~nm})$ were recorded by using UV-visible spectrophotometer. The analysis of the dependence of absorption coefficient on photon energy in the high absorption regions is performed to obtain the detailed information about the energy band gaps of the films [14].

Figure (6) shows the relation between transmittance and wavelength for Co-doped Nickel Oxide thin films. It can be noticed that the transmittance increases rapidly as the wavelength increases in the range of (300- $350 \mathrm{~nm}$ ), and then increases slowly at higher wavelengths. The spectrum shows high transmittance in the visible and infrared regions, and low in the ultraviolet region. It can also be observed that the fundamental absorption edge is sharp in the visible region at the wavelength $(\sim 680 \mathrm{~nm})$ of the spectrum. The maximum transmittance observed of was about $85 \%$ for $\mathrm{Ni}_{0.92} \mathrm{Co}_{0.08} \mathrm{O}$ sample.

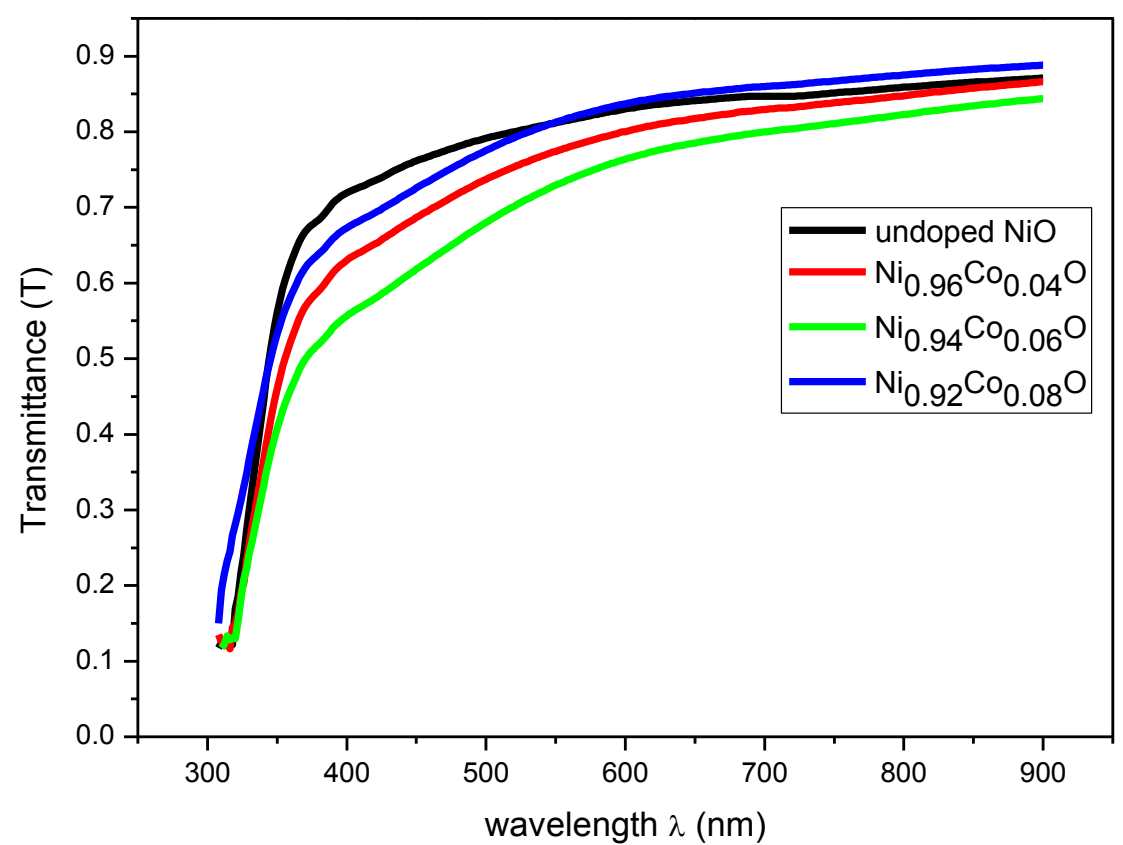

Figure 6. Transmittance $(T)$ versus wavelength $(\lambda)$ for Co- doped Nickel Oxide thin films.

Figure (7) shows the relation between absorbance (A) and wavelength for the deposited thin films. The absorbance decreases rapidly at short wavelengths corresponding to the energy gap of the film. This evident increase of energy is due to the interaction of the material electrons with the incident photons which have enough energy for the occurrence of electron transitions. It is observed that the absorbance increases as the Co-concentration increases. 


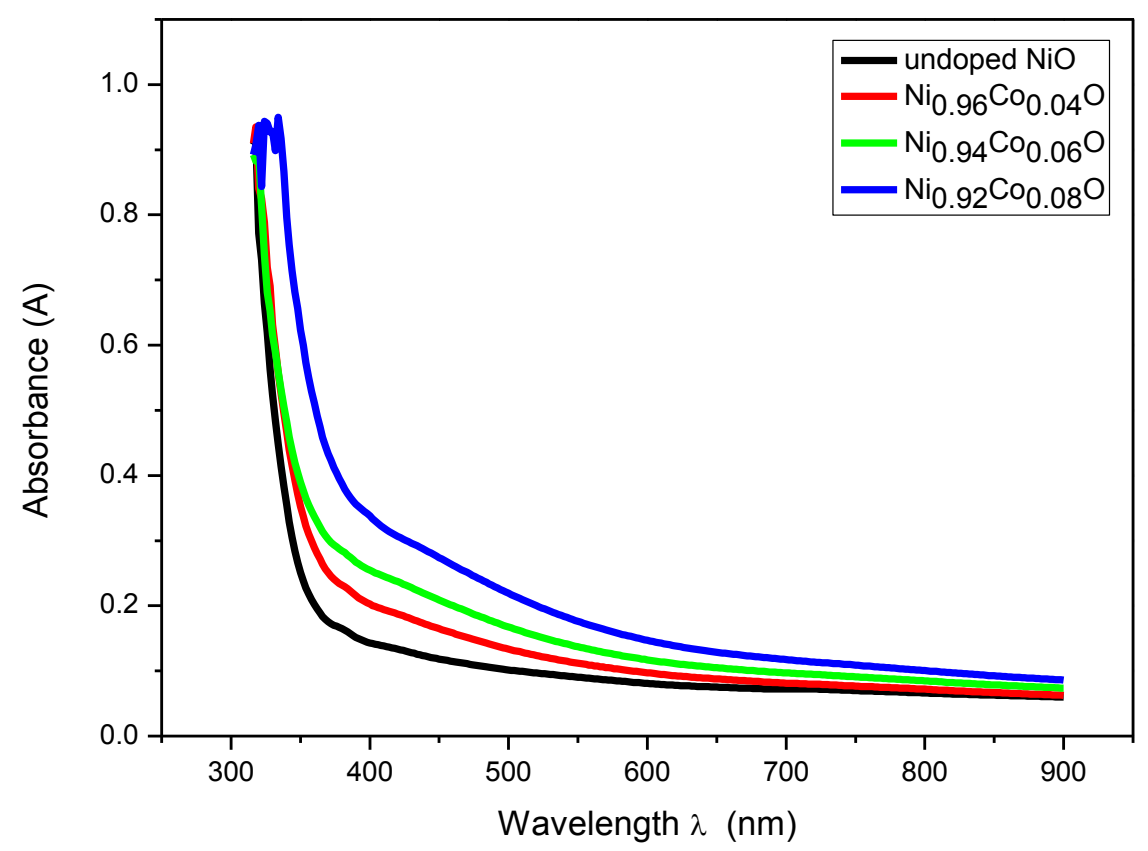

Figure 7. Absorbance (A) versus wavelength $(\lambda)$ for Co-doped Nickel Oxide thin films.

The absorption coefficient can be estimated from the absorbance using the well-known formula [15]:

$$
\alpha=(2.303 \times \mathrm{A}) / \mathrm{t}
$$

where $\mathrm{A}$ is the absorbance, $\mathrm{t}$ is the thickness and $(\alpha)$ is the absorption coefficient. It have been noticed that all the prepared thin films have high absorption coefficient in visible range of spectrum, and this could be seen in Figure (8). The absorption coefficient increases with increase in photon energy (hv). The absorption coefficient of the deposited thin films at different Co doping levels has values of $\left(\alpha>10^{4} \mathrm{~cm}^{-1}\right)$ which implies the increase of the probability of the occurrence of direct transitions.

The optical energy band gap (Eg) is given by the classical relation [15]:

$$
\alpha h v=A\left(h v-E_{g}\right)^{r}
$$

where $\alpha$ is the absorption coefficient, $\mathrm{h} v$ is the photon energy, Eg is the optical band gap, A is a constant which does not depend on photon energy and $r$ has four numeric values $(1 / 2)$ for allowed direct, 2 for allowed indirect, 3 for forbidden direct and $3 / 2$ for forbidden indirect optical transitions. 


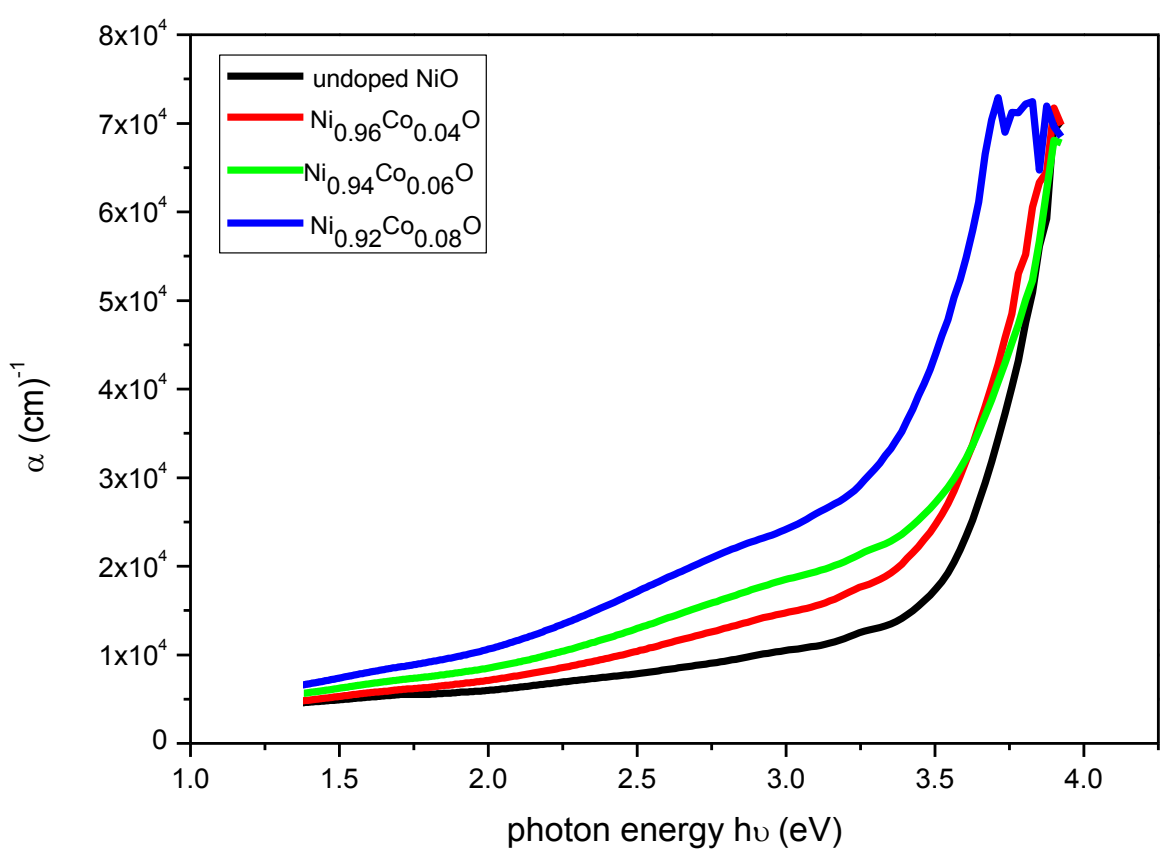

Figure 8. Absorption coefficient versus photon energy for Co-doped Nickel Oxide thin films.

The optical energy band gap (Eg) is given by the classical relation [17]:

$$
\alpha h v=A\left(h v-E_{g}\right)^{r}
$$

where $\alpha$ is the absorption coefficient, $\mathrm{h} v$ is the photon energy, Eg is the optical band gap, $A$ is a constant which does not depend on photon energy and $r$ has four numeric values $(1 / 2)$ for allowed direct, 2 for allowed indirect, 3 for forbidden direct and 3/2 for forbidden indirect optical transitions. In this work, direct band gap was determined by plotting a graph between $(\alpha h v)^{2}$ and $(h v)$ in $\mathrm{eV}$, a straight line is obtained which gives the value of the direct band gap. The extrapolation of straight line to $(\alpha h v)^{2}=0$ gives value of the direct band gap of the material, and this could be seen in Figure (9). We notice that the band gap value decreases with increase in Co-doping concentration $(4,6$, and 8$)$ wt. \%.

The width of the localized states available in the optical band gap of the films affects the optical band gap structure and optical transitions and it is called as Urbach tail, which is related directly to a similar exponential tail for the density of states of either one of the two band edges. The Urbach tail of the films can be determined by the following relation [17]:

$$
\alpha=\alpha_{o} \exp \left(\frac{h v}{E t}\right)
$$

where $\mathrm{E}$ is the photon energy, $\alpha_{o}$ is constant, and $\mathrm{Eu}$ is the Urbach energy which refers to the width of the exponential absorption edge. Figure (9) shows the variation of $(\ln \alpha)$ versus photon energy for the films. The $E_{t}$ values were calculated as the reciprocal of the straight line slopes shown in the figure. Urbach energy increases as the molarity increasing. The obtained 
$\mathrm{E}_{\mathrm{U}}$ values are given in Table (3). Urbach energy increases with increase in Co-doping concentration. The $\mathrm{E}_{U}$ values change inversely with optical band gaps of films.

The refractive index has been calculated using the relation [17]:

$$
n=\left[\frac{(1+R)^{2}}{(1-R)^{2}}-\left(k_{o}^{2}-1\right)\right]^{1 / 2}+\frac{(1+R)}{(1-R)}
$$
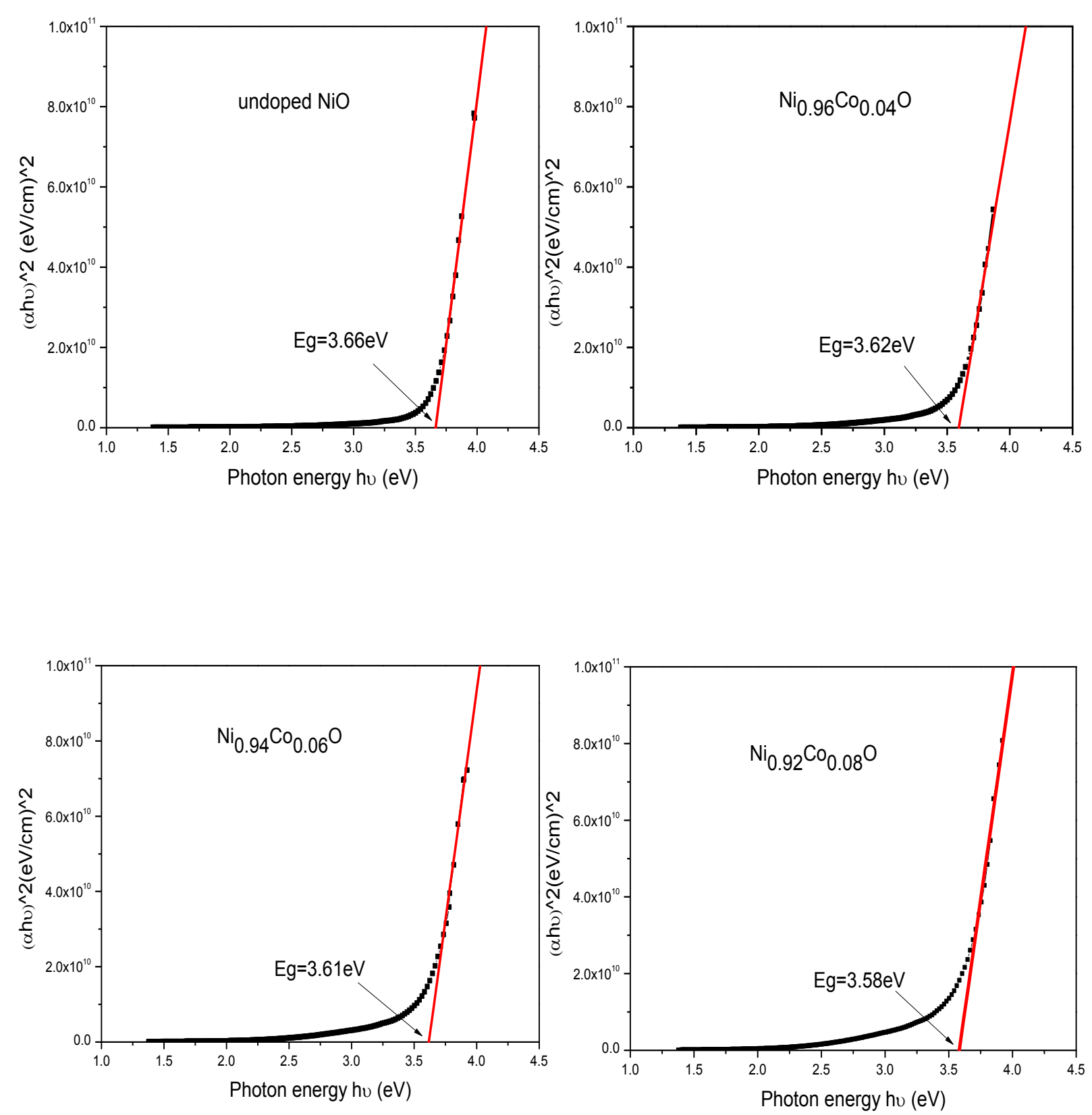

Figure 9. The relation between $(\alpha h v)^{2}$ and (hv) for Co-doped Nickel Oxide thin films. 
where $\mathrm{n}$ is the refractive index, $\mathrm{R}$ is the reflectance and $k_{o}$ is the extinction coefficient. The relation between refractive index and wavelength for $\mathrm{NiO}$ thin films at different molarities is shown in Figure (10). It can be seen that the refractive index of the prepared films have values in the range of $(1.71-2.64)$ which is in agreement with other reports [17,18].

The extinction coefficient $\left(k_{o}\right)$ was calculated using relation [8]:

$$
k_{o}=\frac{\alpha \lambda}{4 \pi}
$$

where $k_{o}$ is the extinction coefficient and $\lambda$ is the wavelength of incident photon.
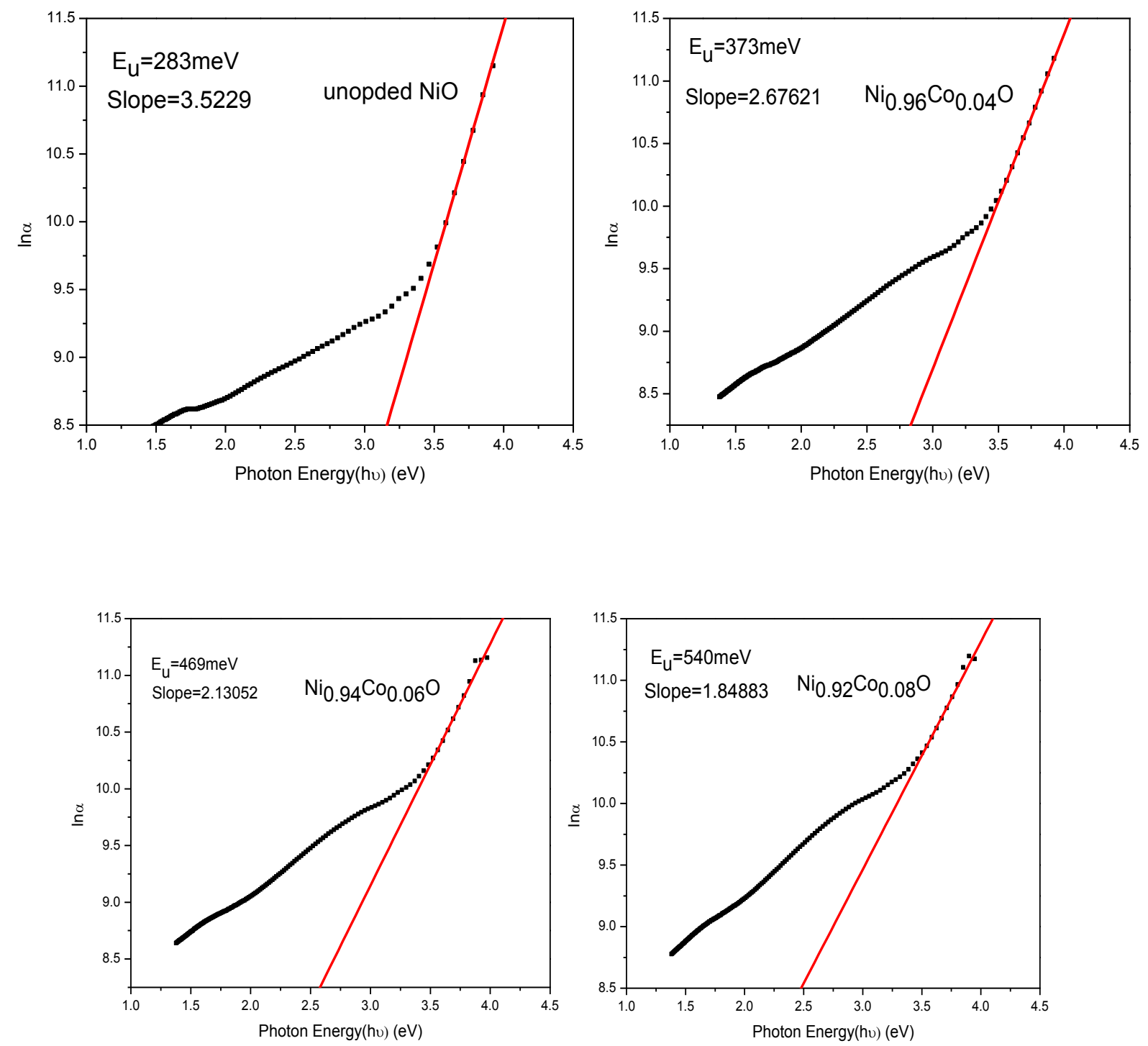

Figure 10. Urbach plots of Co-doped Nickel Oxide thin films. 
Table 3. Urbach Energies $\left(E_{\mathrm{u}}\right)$ of Co-doped Nickel Oxide thin films.

\begin{tabular}{|c|c|}
\hline Cobalt concentration & $\mathrm{E}_{\mathrm{U}}(\mathrm{meV})$ \\
\hline Undoped $\mathrm{NiO}$ & 283 \\
\hline $\mathrm{Ni}_{0.96} \mathrm{Co}_{0.04} \mathrm{O}$ & 373 \\
\hline $\mathrm{Ni}_{0.94} \mathrm{Co}_{0.06} \mathrm{O}$ & 469 \\
\hline $\mathrm{Ni}_{0.92} \mathrm{Co}_{0.08} \mathrm{O}$ & 540 \\
\hline
\end{tabular}

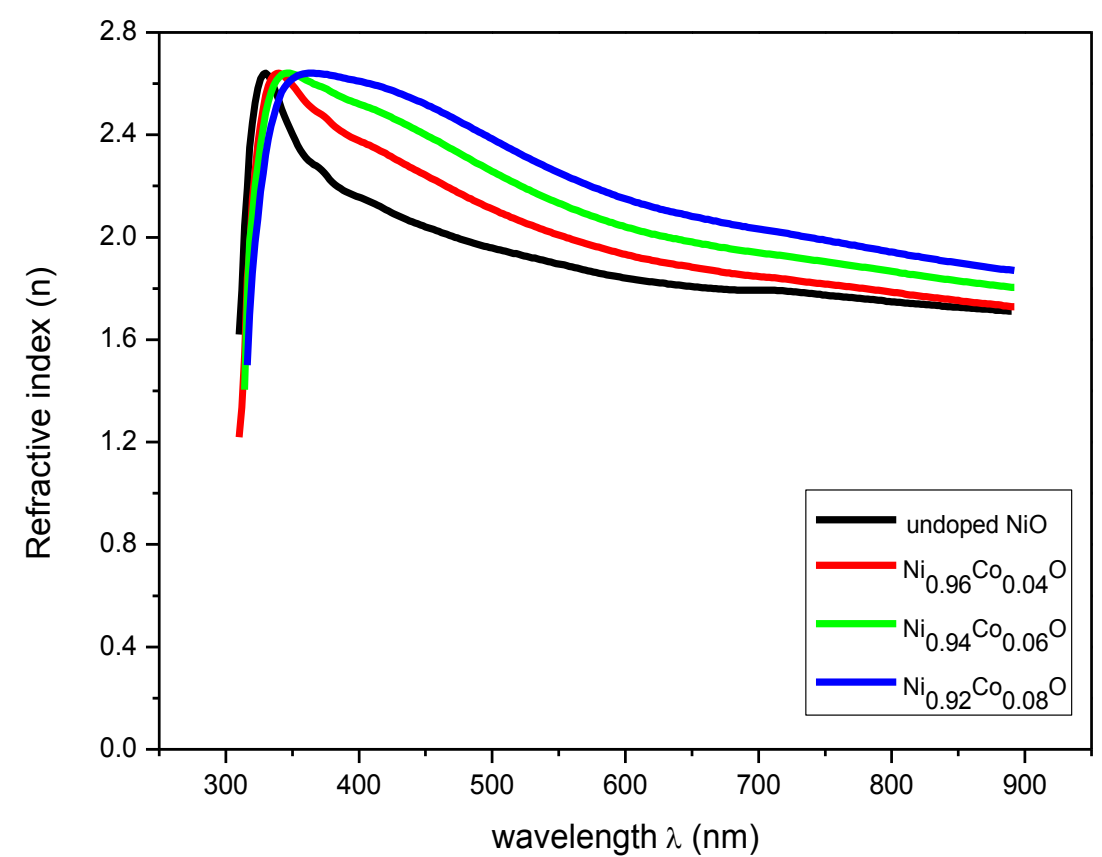

Figure 11. Refractive index versus wavelength of Co-doped Nickel Oxide thin films.

The relation between extinction coefficient and wavelength for Co-doped Nickel Oxide thin films is shown in Figure (11). The extinction coefficient $\left(\mathrm{K}_{\mathrm{o}}\right)$ decreases rapidly at short wavelengths (300-400) $\mathrm{nm}$ and after that the value of $\left(\mathrm{K}_{\mathrm{o}}\right)$ remains almost constant. The rise and fall in the value of $\left(\mathrm{K}_{\mathrm{o}}\right)$ is directly related to the absorption of light. The lower value of $\left(\mathrm{K}_{\mathrm{o}}\right)$ in the wavelength range (400-900) $\mathrm{nm}$ implies that these films absorb light in this region very easily. Results show that the extinction coefficient values of Co-doped Nickel Oxide thin films are in the range of $(0.032-0.18)$.

The dielectric constant can be represented by the folowing equation [18]:

$$
\varepsilon=\varepsilon_{1}-\mathrm{i} \varepsilon_{2}
$$

where $\varepsilon_{1}$ is the real part of the complex dielectric constant and $\varepsilon_{2}$ is the imaginary part of it. For the calculation of the dielectric constant in its two parts one can use the following expressions:

$$
\varepsilon_{1}=\mathrm{n}^{2}-\mathrm{ko}{ }^{2}
$$




$$
\varepsilon_{2}=2 n \mathrm{ko}
$$

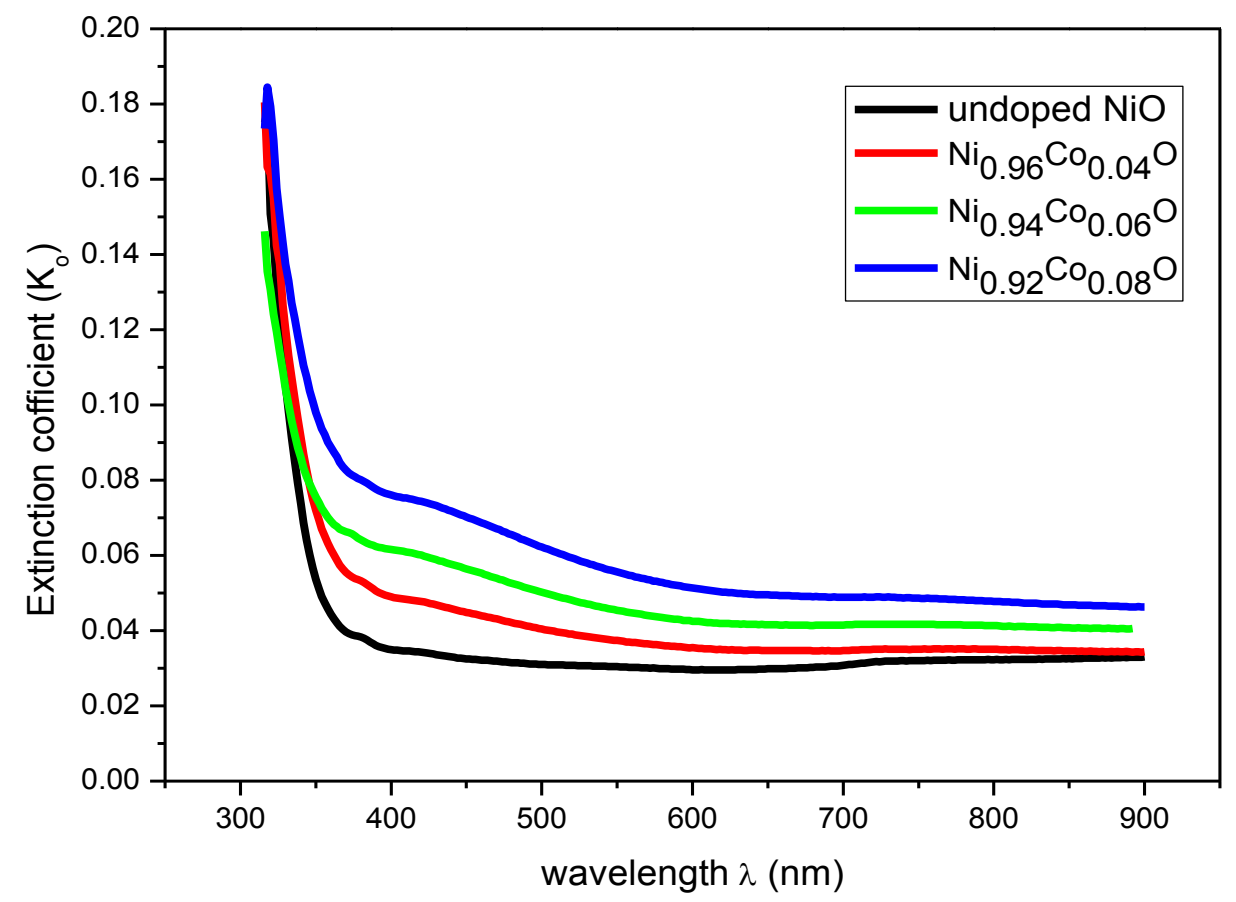

Figure 12. Extinction coefficient versus wavelength of Co-doped Nickel Oxide thin films.
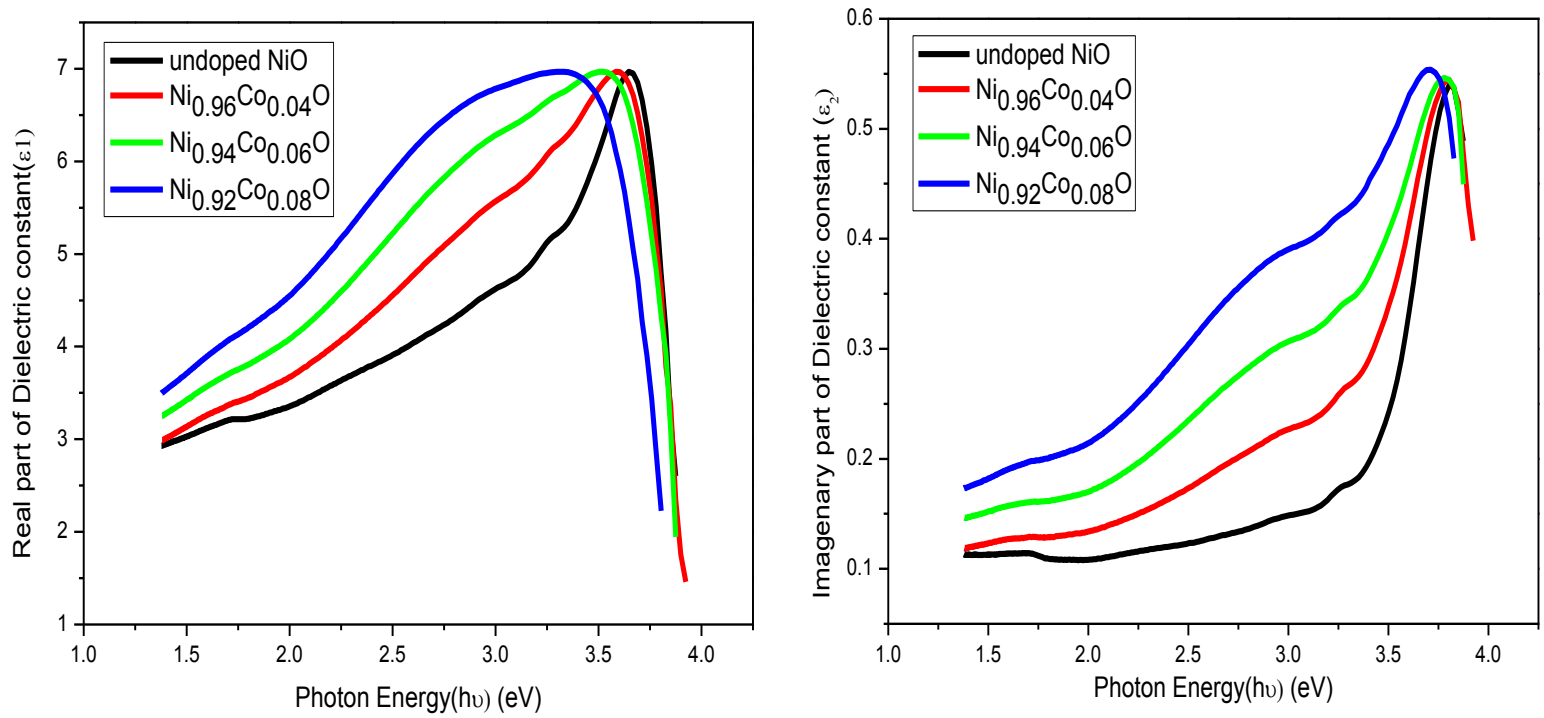

Figure 13. Real and imaginary parts of dielectric constant versus photon energy of Co-doped Nickel Oxide thin films.

The relation between real and imaginary parts of dielectric constant and photon energy for Co-doped Nickel Oxide thin films is show in Figure (13). It can be seen that both the real and imaginary parts of the dielectric constant increase as photon energy increases in the range 
of (1.25-3.5) eV and after that the value of the real and imaginary parts decrease. It is observed that both the real and imaginary parts of the dielectric constant increases with increase in Co-doping concentration.

\section{CONCLUSIONS}

In this study Nickel-Cobalt Oxide $\left(\mathrm{Ni}_{(1-\mathrm{x})} \mathrm{Co}_{\mathrm{x}} \mathrm{O}\right)$ thin films, where $\mathrm{x}=0,4,6$ and $8 \%$ were successfully deposited on glass substrate at $\left(400{ }^{\circ} \mathrm{C}\right)$ by chemical spray pyrolysis technique using Nickel and Cobalt nitrates as the Ni and Co source. XRD patterns of the Codoped Nickel Oxide thin films indicate that all films are polycrystalline with cubic face centered crystal structure. The main characteristic peaks are assigned to the (111), (200) and (220) planes. AFM results showed homogenous and smooth thin films. The undoped NiO thin film has highest grain size, average roughness and RMS roughness. The transmittance of Codoped Nickel Oxide thin films increases rapidly as the wavelength increases in the range of $(300-350) \mathrm{nm}$, and then increases slowly at higher wavelengths. The band gap decreases as the Co-concentration increases and the band gap values range between $3.66 \mathrm{eV}$ and $3.58 \mathrm{eV}$. The Urbach energy increases as the Co-concentration increases and the Urbach energy values range between $283 \mathrm{meV}$ and $540 \mathrm{meV}$.

\section{References}

[1] P. Pradniak, "Handbook of Inorganic Chemicals", McGraw-Hill Publications, 2002.

[2] N. Greenwood, A. Earnshaw, "Chemistry of the Elements". Oxford, Pergamon Press. 1984.

[3] K. Lascelles, L. G. Morgan, D. Nicholls, D. Beyersmann, "Nickel Compounds", in Ullmann's Encyclopedia of Industrial Chemistry, Wiley-VCH, Weinheim, 2005.

[4] E. Fujii, A. Tomozawa, H. Torii, R. Takayama, Jpn. J. Appl. Phys. 35 (1996) 328-330.

[5] H. Sato, T. Minami, S. Takata, T. Yamada, Thin Solid Films 236 (1993) 27-31.

[6] R. Cerc Korosec, P. Bukovec, B. Pihlar, A. Surca Vuk, B. Orel, G. Drazic, Solid State Ionics, 165 (2003).

[7] M. Caglar, S. Ilcan, Y. Caglar, Trakya Univ. J. Sci. 7(2) (2006) 153.

[8] A. F. Saleh, International Journal of Application or Innovation in Engineering \& Management 2(1) (2013) 16.

[9] C. Barret, Massalki T. B. , " Structure of Metals ", Oxford Pergamon, (1980).

[10] A.R. Balu, V.S. Nagarethinam, N. Arunkumar, M. Suganya, Journal of Electron Devices 13 (2012) 920-930.

[11] R. A. Ismail, S. Ghafori, G. A. Kadhim, Appl. Nanosci. 3 (2013) 509-514.

[12] V. D. Mote, Y. Purushotham, B. N. Dole, Journal of Theoretical and Applied Physics 6(6) (2012).

[13] C. Barret, T. B. Massalki, "Structure of Metals", Oxford Pergamon, 1980. 
[14] B. Sahin, F. Bayansala, M.Yukselc, N. Biyiklib, J. Ceramics International 40 (2014) 5237-5243.

[15] J. I. Pankove, "Optical Process in Semiconductors", Dover Publishing, Inc., New York, 1971.

[16] C. F. K. Lingshirn, "Semiconductor Optics", Springer Verlag, Berlin Hridelberg, $\left(1^{\text {st }}\right.$ ed.), 1997.

[17] Nibras F. Al.Shammary, Journal of Kufa-Physics 2(1) (2010).

[18] S. S. Ahmed, E. K. Hassan, G. H. Mohamed, International Journal of Advanced Research 2(2) (2014) 633-638.

( Received 18 October 2014; accepted 28 October 2014 ) 